\title{
Thin-Film Inductor Designs and Materials for High-Current Low-Voltage Power
}

\author{
Charles R. Sullivan, Satish Prabhakaran, Parul Dhagat, Yuqin Sun \\ Thayer School of Engineering, Dartmouth College, Hanover, NH 03755-8000, USA
}

Thin-film inductors for dc-to-dc converters for microprocessor power delivery are discussed. Thin-film inductors offer small size and fast transient response as required by the application. The choice of magnetic material and design of the inductor are discussed. Composite granular metal-nonmetal films applied in a Vgroove stucture show strong promise for this application. The possibility of using magnetic films with stripe domains is also discussed.

Key words: soft magnetic material, inductors, thin-film, dcto-dc converters, power converters.

\section{Introduction}

Low voltages, high currents and fast load transients are emerging challenges in power delivery for highperformance digital electronics such as microprocessors. Power converters for these applications need to have fast response, high efficiency and small size. The inductor in the power converter plays a central role in determining the performance each of these aspects. Thin-film inductors offer possible advantages 1)-16). However, these applications require higher efficiency, higher power density, and higher current than is offered by most thinfilm inductors. In order to meet these requirements, we are studying both magnetic materials and inductor designs. As a typical example, we are fabricating inductors for a $3.3 \mathrm{~V}$ to $1.1 \mathrm{~V}, 7 \mathrm{~A}$ dc-dc power converter operating between $1 \mathrm{MHz}$ and $50 \mathrm{MHz}$.

\section{Magnetic Materials}

Microfabricated magnetic components are often made with thin layers of magnetic material to reduce eddy current losses. This is effective at controlling loss resulting from magnetic flux traveling in the plane of the film, but flux components out of the plane can still induce eddy currents that result in substantial losses ${ }^{17)}$. Granular composite magnetic materials can be used instead of multi-layer thin films to effectively control eddy-current loss due to flux in and out of the plane of the film. These materials consist of nanoscale particles of Co or other magnetic metals in a ceramic matrix such as $\mathrm{Al}_{2} \mathrm{O}_{3}$. Conventionally, they are deposited using reactive sputtering of an alloy target (e.g., ${ }^{18)},{ }^{19)},{ }^{20)}$ ). When a CoAl target is sputtered in the presence of a small amount of oxygen, the $\mathrm{Al}$ ideally combines with $\mathrm{O}$, leaving $\mathrm{Co}$ to form a separate phase.

We have also experimented with depositing similar materials by evaporation, using $\mathrm{Co}$ and $\mathrm{MgF}_{2}$ sources ${ }^{21)}$. We are presently using reactively sputtered $\mathrm{Co}-\mathrm{ZrO}_{2}$ films ${ }^{22)}$. A Halbach array ${ }^{23}$ is used during deposition to provide a highly uniform magnetic field in the substrate region.

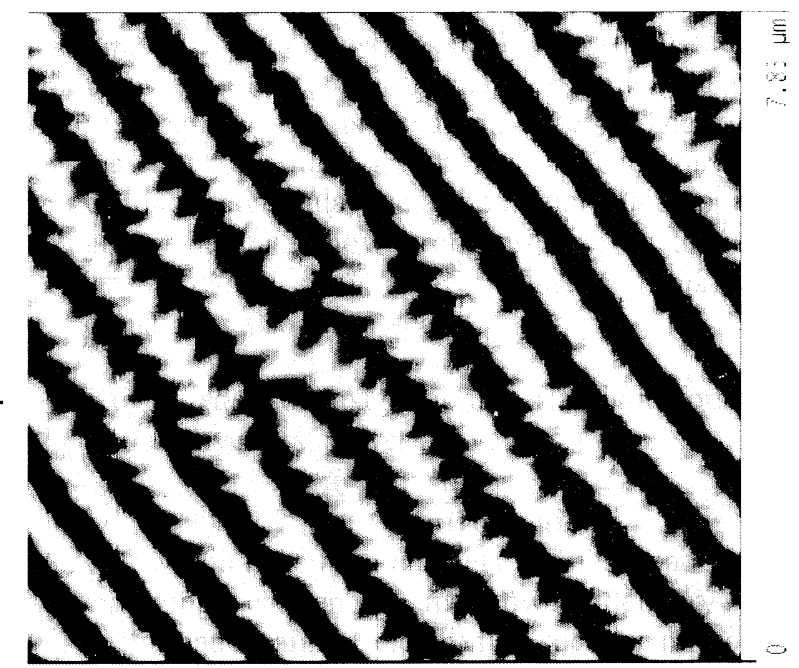

Fig. 1. MFM image of stripe domains in $\mathrm{Co}-\mathrm{ZrO}_{2}$

In several different granular materials, we have observed the formation of stripe domains (Fig. 1), which result in dramatically different magnetic properties ${ }^{24)}$. The stripedomain hysteresis loop, shown in Fig. 2 includes a lossy open loop in the central region, but at moderate fields it has lower permeability regions associated with domain rotation, circled in Fig. 2. The image in Fig. 1 also shows some cross-tie walls between stripes. We are not aware of any significant effects this has on the hysteresis loop shown in Fig. 2. In some applications, the lossy central region of Fig. 2 cannot be avoided, and stripe domains are considered detrimental. However, in dc-to-dc converters, inductors typically operate with unidirectional current, and thus unidirectional flux. For these applications, it may be possible to make use of the low-permeability region for power-converter applications. Although the available flux swing is reduced with stripe domains, the low permeability allows high $H$ values without saturation, similar to a high $H_{k}$ value.

To confirm that operation in this region does produce low hysteresis, we measured a minor hysteresis loop in the same stripe-domain sample the one shown in Fig. 2. The resulting loop, shown in Fig. 3, confirms that low hysteresis is possible in a stripe-domain material with the unipolar drive common in power-converter applications. Note that although the loop in Fig. 2 is only closed above about 100 Oe (or below -100 Oe), the loop in Fig. 3 starts at zero applied field and is closed throughout. This is because the excitation would need to go negative (to about $-100 \mathrm{Oe}$ ) to flip cause the lossy switching transition seen in Fig. 2; in Fig. 3, the domains rotate but maintain the same configuration without a lossy switching transition. 


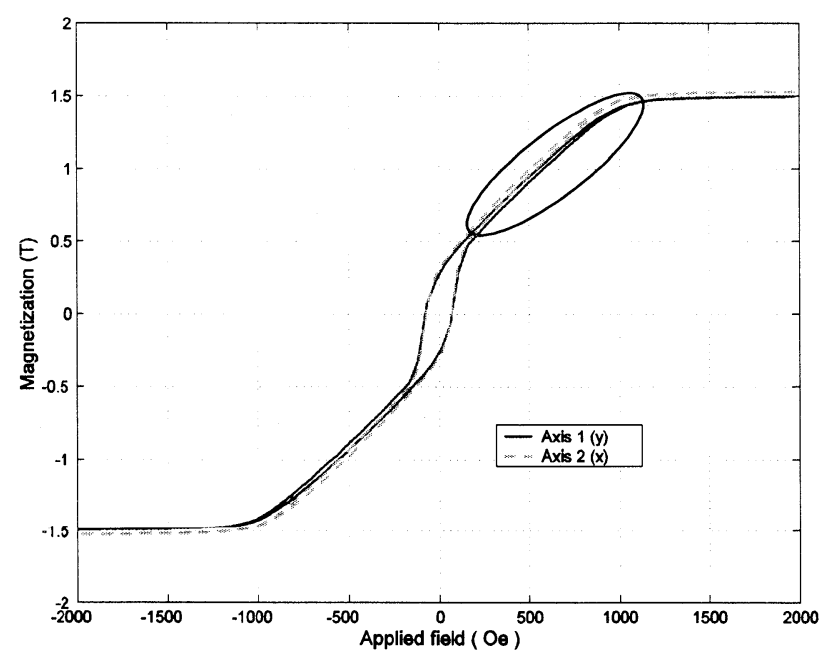

Fig. 2. Hysteresis loop of $\mathrm{Co}-\mathrm{MgF}_{2}$ with stripe domains. This circled region has low hysteresis loss and may be an attractive region to operate in. The film was deposited as described in ${ }^{21)}$, using co-evaporation of Co $(89 \mathrm{v} \%)$ from an e-beam source and $\mathrm{MgF}_{2}$ from a thermal source. The subtrate temperature was $140{ }^{\circ} \mathrm{C}$; the Co deposition rate was $30 \AA / \mathrm{s}$, the base pressure before deposition started was $1.8 \times 10^{-6}$ torr, and the incident angle of the deposition was 6.5 degrees away from being perpendicular to the substrate. No magnetic field was applied during deposition.

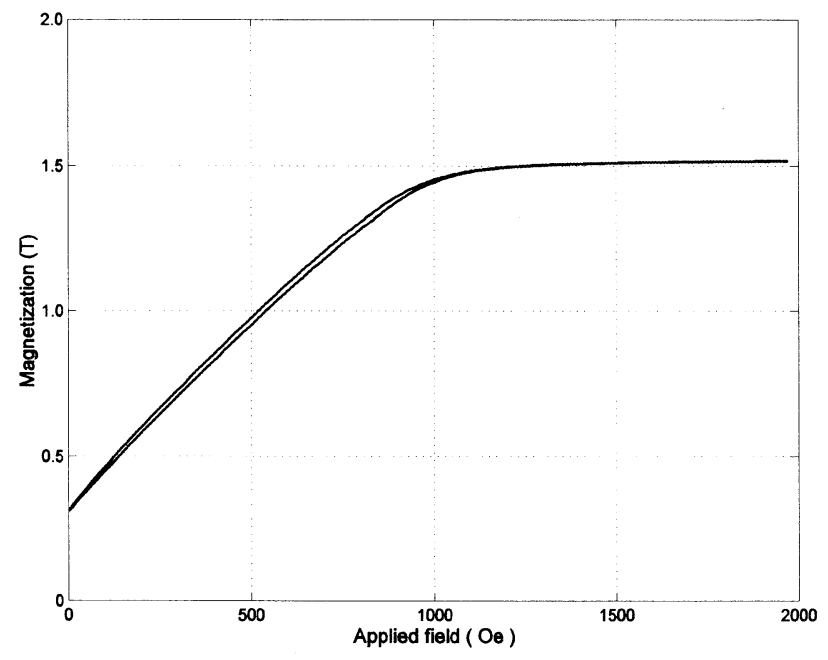

Fig. 3. Minor hysteresis loop of the same Co-MgF sample as in Fig. 2 with asymetrical drive, similar to that in many dc-to-dc converter circuits. The material operates in a region similar to that circled in Fig. 2 and has low loss.

Whether the disadvantages of stripe domains outweigh the advantages probably depends on the application. The engineering of deposition parameters to control stripe domain formation is discussed in ${ }^{24)}$.

\section{Design}

An inductor or transformer with a closed magnetic core consists of two interlinked loops: one is conductor and one is magnetic material. In most cases the conductor loop comprises multiple turns, although for low-voltage, highcurrent applications, the impedance is low enough that a single turn is optimal. In any case, interlinking the two requires at least three deposition steps. In ${ }^{25)}$ these two approaches were compared, using a theoretical analysis of power density and efficiency. The designs in the class using two depositions of magnetic material are termed pot-core designs, because, like a conventional pot-core transformer, they have magnetic material surrounding a coil. The designs in the class using two depositions of conductor are termed toroidal designs, because, like a conventional toroidal transformer, they have a coil surrounding a core. In ${ }^{25)}$, it was shown that using two magnetic layers (the "pot-core" design) results in higher power density for a given efficiency. In addition, it is difficult to achieve high efficiency in toroidal designs using anisotropic magnetic materials, because the direction of flux is different in different regions. In multiturn designs, a critical parameter is the aspect ratio in the conductor patterning, because, for a given resolution, it determines the thickness and thus the resistance of the winding. Much progress has been made in developing high-aspect ratio winding processes ${ }^{3}$. However, for lowvoltage high-current applications, with a single turn, conductor aspect ratio is much less important. Instead, the overall space available within the core for the conductor and the ac resistance of the conductor become the important factors.

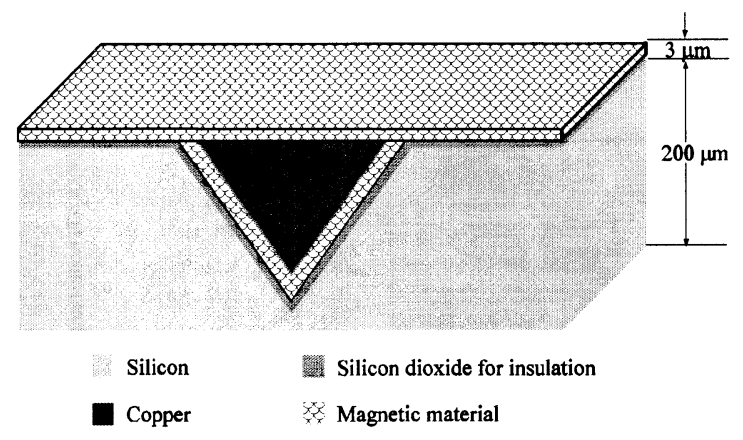

Fig. 4. Schematic of V-groove inductor (not to scale).

\section{V-Groove Inductor}

The "V-groove" design and fabrication process ${ }^{17)},{ }^{26)}$, ${ }^{27)}{ }^{28)}$ are intended specifically to maximize power density and efficiency in high-current low-voltage applications. The inductor design is in the form of a triangular wire surrounded by magnetic material, embedded in a silicon substrate as shown in Fig. 4. The fabrication process for these devices can be summarized as follows; more details are provided in ${ }^{28)}$. A V-trench is formed by anisotropic etching of a silicon substrate. Composite magnetic material consisting of $\mathrm{Co}-\mathrm{ZrO}_{2}$ is deposited in the trench to form the core. Copper is filled in the groove to form the conductor and an overlayer of core material completes the core of the inductor. The magnetic material is wrapped around a single wire thus forming a one-turn inductor. 
To achieve high performance, it is important to perform design calculations that specifically address the application of interest. These calculations are discussed in ${ }^{17)},{ }^{26)},{ }^{29}$. Depending upon the specific assumptions about the magnetic material and the geometrical constraints, we predict performance of 50 to $200 \mathrm{~W}$ of power converter output per square centimeter of inductor substrate area with inductor efficiency of 85 to $90 \%$ or better, based on an $8 \mathrm{MHz}$ converter switching frequency. Recent analysis has addressed optimization of the complete power converter, including area and losses in the power FETs ${ }^{29)}$. This work indicates that, for FETs implemented in an advanced low-voltage CMOS process, higher switching frequencies, in the 20 to $50 \mathrm{MHz}$ region, may be advantageous to allow even higher power densities.

Our first prototype $\mathrm{V}$-groove inductors ${ }^{30}$ ) were used to test the fabrication process, but were smaller than the designs required for high-performance in the ultimate application. The characteristics measured using the techniques described in ${ }^{31)}$ were close to our predictions, although the scaled-down devices are not capable of high efficiency or power density.

\section{Conclusion}

Granular magnetic materials offer performance advantages for thin-film magnetic components. For lowvoltage, high-current applications, the $\mathrm{V}$-groove design offers high performance combined with a simple fabrication process.

Acknowledgment This work was supported in part by Intel Corporation and by the United States National Science Foundation under grant ECS-9875204.

\section{References}

1 ) H. J. Kim, H. J. Kim, J. R. Kim, K. H. Kim, and S. H. Han: International Magnetics Conference (2002).

2 ) J. Boggetto, Y. Lembeye, and J. K. J.P. Ferrieux: 33rd Annual Power Electronics Specialists Conf. (2002).

3) M. Brunet, T. O'Donnell, J. O'Brien, P McCloskey, and C, O'Mathuna: 16th Annual IEEE Applied Power Electronics Conference and Exposition (2001).

4) M. Edo et al., IEEE Trans. on Mag. 36, 3518 (2000).

5) M.G. Allen, J. Y. Park, J.-W. Park, and Y.-H. Joung;, IEEE Trans. on Mag. 25, 106 (2002).

6) S. Airam. and G. Salmer, IEEE Trans. on Pow. Elec. 16, 594 (2001).
7) K. Yamasawa, K. Maruyama, I. Hirohama, and P. Biringer, IEEE Trans. on Magn. 26, 1204 (1990).

8) K. Yamaguchi, E. Sugawara, O. Nakajima, and H. Matsuki, IEEE Trans. on Magn. 29, 3207 (1993).

9) K. Yamaguchi et al., IEEE Trans. on Magn. 29, 2232 (1993).

10) M. Mino, K. Tsukamoto, K. Yanagisawa, A. Tago, and T. Yachi: Proceedings of Applied Power Electronics Conference, APEC'96, p. 422-426 (1996).

11) C. R. Sullivan and S. R. Sanders, Measured performance of a high power-density microfabricated transformer in a dc-dc converter: 27thAnnual Power Electronics Specialists Conf., volume 1, p. 287-294 (1996).

12) T. Sato et al., J. of Applied Physics 83, 6658 (1998).

13) L. Daniel, C. R. Sullivan, and S. R. Sanders IEEE Transactions on Power Electronics., 14, 709 (1999).

14) V. Korenivski and R. B. van Dover, IEEE Trans. on Magn.34, 1375 (1998).

15) Y. Sasaki et al., NanoStructured Materials 8, 1025 (1997).

16) M. Xy, T. M. Liakopoulos, C. H. Ahn, S. H. Han, and H. J. Kim, IEEE Trans. on Magn. 34, 1369 (1998).

17) G. J. Mehas, K. D. Coonley, and C. R. Sullivan: IEEE AppliedPower Electronics Conference (1999).

18) S. Ohnuma, H. Fujimori, S. Mitani, and T. Masumoto, $J$. Appl. Phys. 79, 5130 (1996).

19) Y. Hayakawa and A. Makino, NanoStructured Materials 6 , 989 (1995).

20)Y. Hayakawa, A. Makino, H. Fujimori, and A. Inoue, J. Appl. Phys. 81, 3747 (1997).

21) K. Coonley, G. Mehas, C. Sullivan, and U. Gibson, IEEE Trans. Magn. 36 (2000).

22) S. Ohnuma, H. Lee, N. Kobayashi, H. Fujimori, and T. Masumoto, IEEE Trans. on Magn. 37, 2251 (July 2001).

23) H. Klaus, Nuclear Instruments and Methods 169 (1980).

24) P. Zou, W. Yu, and J. Bain, IEEE Trans. Magn. 38, 3501 (Sept. 2002).

25) C. Sullivan and S. Sanders, IEEE Trans. on Pow. Elec. 11 (1996).

26) G. J. Mehas, K. D. Coonley, and C. R. Sullivan: 31 st IEEE Annual Power Electronics Specialists Conference (2000).

27) S. Prabhakaran, D. Kreider, Y. Lin, and C. Sullivan: IEEE International Workshop on Integrated Power Packaging, $\mathrm{p}$. 102-5 (2000).

28) S. Prabhakaran, C. R. Sullivan, and C. G. Levey: Advanced Technology Workshop on Integrated Power Passives (2002).

29) K. Venkatachalam, Optimization of microfabricated buck converters, Master's thesis, Thayer School of Engineering, Dartmouth College, 2002.

30) S. Prabhakaran, C. Sullivan, and K. Venkatachalam: Intermag, abstract EA-06 (2003).

31) S. Prabhakaran and C. R. Sullivan: Techniques for high power and lowimpedance: IEEE Industry Applications Society Annual Meeting (2002).

(Received September 1, 2003; Accepted October 29, 2003) 